\title{
Step-Function Approach for E-Learning Personalization
}

\author{
Sfenrianto* ${ }^{* 1}$, Zainal A. Hasibuan ${ }^{2}$ \\ ${ }^{1}$ Master in Information Systems Management, Bina Nusantara University, Jakarta, Indonesia \\ JIn. Kebon Jeruk Raya 27, Jakarta, Indonesia telp: +62-21-53696999, fax: +62-21-535,0655 \\ ${ }^{2}$ Faculty of Computer Science, University of Indonesia, Jakarta, Indonesia \\ Kampus UI Depok 16424 Indonesia, telp: +62-21-7863419, fax: +62-21-7863415 \\ ${ }^{*}$ Corresponding author, e-mail: sfenrianto@binus.edu ${ }^{1}$; zhasibua@cs.ui.ac.id ${ }^{2}$
}

\begin{abstract}
Personalization is an alternative to improve the learning process for an e-Learning environment. It is a useful strategy to adjust the student' needs based on their characteristics to make learning more effectively. In this study, we propose the step-function approach for personalization in e-learning. It provides the students with adopting the knowledge-ability factor (Novice, Average, or Good category) that matches with their learning materials levels (Level1, Level2, or Level3). The approach implemented into an e-learning which called SCELE-PDE and used as the experimental group in two stages with different scenarios. In the first, without a step-function approach, but the SCELE-PDE can identify an initial of student's ability to knowledge category. The second stage has used the approach to providing students with personalization in e-Learning to adapt learning material based on a knowledge category. As a result, the step-function approach has successfully to improve the student performance in the learning process during the course. Thus, the approach has shown an increase in the level of students' knowledge. So, it can be used as a guide when designing an e-learning personalization for students to enhance learning and achievement.
\end{abstract}

Keywords: Step-Function, e-Learning, Personalization, Knowledge-Ability Factor, Knowledge-Ability Categories

Copyright (c) 2017 Universitas Ahmad Dahlan. All rights reserved.

\section{Introduction}

The e-Learning systems have benefited by facilitating students to learn anytime, anywhere, and anyhow. In the system, different ability, learning style, motivation, and so on as important factors to consider. The challenge is the provision of personalization with adapting the learning material matches those factors, so that makes learning easier for student and affect their performance. Moreover, in the study of personalization [1] as well claim that personalized effect student achievement positively. The affective states and learning style tactics to provide personalized in the e-learning system has a significant effect on student learning [2]. In research on personalized by adapting motivation and interest from students have positive effects on learning process [3]. Then, by providing personalization based on the student's ability in online learning can enhance student's learning performance [4].

To optimize the e-learning process could be done using personalization approach. The personalization of e-learning could facilitate the delivery of learning content based on the students' needs [5]. Then, it can be easily represented learning materials based on students' factors [6]. Besides, the results our previous study showed, the learning types based on learning style, motivation, and knowledgeability (triple-factor) in the e-learning process successfully improve the learning process and its outcomes through learning recommendation and personalization [7-8]. In studies [6] have used some different factors such as students' ability, prior knowledge, their motivation, and learning style for delivering personalized learning material. Thus, the personalization should be designed to facilitate a learning material which matches the influence diverse factors of students' learning to ensure that each student will receive the learning material according to those factors.

In order to provide an e-Learning personalization based on those factors are referred to studied by some previous researchers. Table 1 shows the factors and approaches based on some relevant studies. These works differ in terms of factors and approaches that are considered for the e-learning personalization. 
Table 1. Summary of the Studies

\begin{tabular}{|c|c|c|}
\hline Factors & Approaches & Studies \\
\hline $\begin{array}{l}\text { learner's ability, learning style, preferences, and levels of } \\
\text { knowledge }\end{array}$ & Ontology & [6] \\
\hline Learning Style and Learning behaviors & Two-source adaptive learning & [9] \\
\hline Learning Style, Motivation & Ontology & [10] \\
\hline learner's behaviors, interests, and habits Knowledge & Fuzzy Item Response Theory (FIRT) & [11] \\
\hline Ability & $\begin{array}{l}\text { Item Response Theory (IRT) and } \\
\text { Artificial Neural Network (ANN) }\end{array}$ & [12] \\
\hline Ability & $\begin{array}{l}\text { Data-driven approach and literature } \\
\text { based approach }\end{array}$ & [13] \\
\hline Learning Style & Learning Strategies (LSC) & [15] \\
\hline Learning Style & Unified Modeling Language (UML) & [16] \\
\hline Preference and knowledge level & $\begin{array}{l}\text { Adaptive E-learning based on the IEEE } \\
1484 \text { LTSA }\end{array}$ & [17] \\
\hline
\end{tabular}

Accordingly, this paper focuses on the research question, "how to propose a stepfunction approach for an e-Learning personalization based on the knowledge-ability factor?". At the moment, there are no similarities researchers have been discussing the step-function approach. It is for implementing personalizes to base on the student's ability to knowledge level. Thus, the step-function contributes as an alternative approach to the research in this field. The paper is structured in the next sections as follows: step-function approach and research method; subsequently, experimental results; the last section concludes our study.

\section{Step-Function Approach}

The e-Learning system has provided facilities for instructors and students to support a learning process. However, the system does not have the facilities to provide suitable personalized learning materials for students according to their knowledgeability categories. In the study, Step Function is implemented based on knowledge-ability categories. Figure 1, explain all content uploaded into the e-Learning system by the instructors. They were also giving assignments and providing online quizzes, on the system. Meanwhile, the students will gain the learning materials that suit their needs, uploaded assignments and take quizzes. The system will determine the knowledge-ability category based on the assessment score and quiz score. In Table 2, the knowledge-ability divided into three categories based on a particular scale of scores.

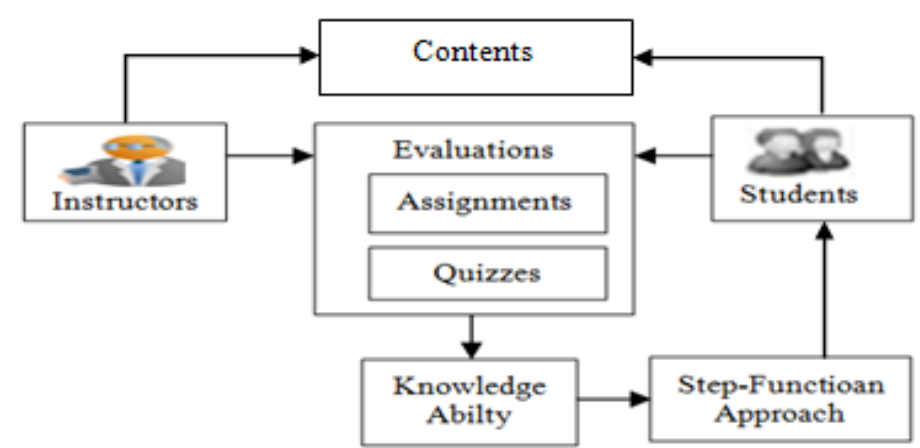

Figure 1. E-Learning personalization for step-function approach

Table 2. Knowledge-Ability Category

\begin{tabular}{cc}
\hline Scale Scores & Categoties \\
\hline $0-75$ & Novice $\left(\mathrm{KA}_{1}\right)$ \\
$76-85$ & Average $\left(\mathrm{KA}_{2}\right)$ \\
$86-100$ & Good $\left(\mathrm{KA}_{3}\right)$ \\
\hline
\end{tabular}


After student knowledge-ability obtained, the system will provide personalized learning material for students. Table 3, explain the material levels and learning contents.

Table 3. Material Levels and Contents

\begin{tabular}{cc}
\hline Material Levels & Contents \\
\hline Level $_{1}$ & Outline and material $\left(\mathrm{LM}_{1}\right)$ \\
$\mathrm{Level}_{2}$ & Outline, material, and example $\left(\mathrm{LM}_{2}\right)$ \\
$\mathrm{Level}_{3}$ & Outline, material, example, and reference $\left(\mathrm{LM}_{3}\right)$ \\
\hline
\end{tabular}

Then, the step-function for personalization learning materials base on knowledge-ability can be created as shown in Figure 2. It delivers the material level according to the knowledge category. Thus, the e-Learning system will provide suitable the material which must be learned based on the category. The step-function consisting of three steps, namely:

1. The first step is a good category $\left(K_{1}\right)$. The e-Learning is required to provide material Level ${ }_{1}$, denote $\left.f\left(K A_{1}\right)=L M_{1}\right)$. In this condition, the student is assumed that the category has understood the course better, so given only an outline and material.

2. The second step is an average category $\left(\mathrm{KA}_{2}\right)$. The e-Learning is required to provide material Level $\left.\right|_{2}$, denote $\left.f\left(K_{2}\right)=L M_{1} \cup L M_{2}\right)$. This condition assumed the student besides needing both outline and materials, they also need the example of further explanation or real implementation about some topic in learning.

3. The final step is a novice category $\left(\mathrm{KA}_{3}\right)$. The e-Learning is required to provide material Level ${ }_{3}$, denote $\mathrm{f}\left(\mathrm{KA}_{3}\right)=\left(\mathrm{LM}_{1} \cup \mathrm{LM}_{2}\right) \cup \mathrm{LM}_{3}$. This condition is assumed that novice category, needing all materials (i.e. outline, material, example, and a reference to sharpen students understanding the topic in learning).

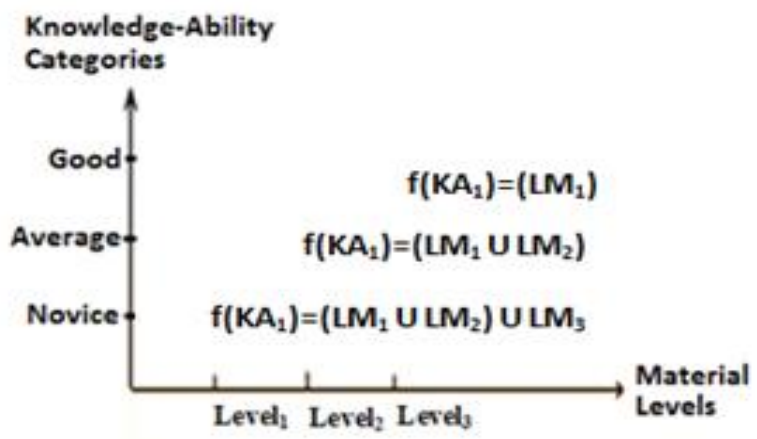

Figure 2. The Step-Function approach for personalization learning materials

\section{Research Method}

The method or approach used in this study is an experiment research. The experiment was conducted to implement and analyzed the step-function approach at Faculty of Computer Science, University of Indonesia (Fasilkom UI). It was involved 100 students who took "Scientific Writing" course in the odd semester 2012/2013. During the learning, the students were required to interact with the SCELE-PDE system during 12 weeks. Figure 3, shows the result of the system interface, which facilitates the Step-Function approach utilized in this experiment.

The experiment scenario and evaluation of results were carried out in two stages. The first stage was conducted from Week 1 to 7 through the SCELE-PDE, without the use of StepFunction approach. The stage was being used to identify the initial of student's knowledgeability. Table 4 shows, learning topics that have been taught to the student. At this stage, each student is taught the same material. 
Table 4. Learning Topics and Contents

\begin{tabular}{cl}
\hline Weeks & \multicolumn{1}{c}{ Topics } \\
\hline Week $_{1}$ & What is Scientific Writing \\
Week $_{2}$ & Fundamental concepts of science \\
Week $_{3}$ & Scientific inquiry and logical thinking \\
Week $_{4}$ & Writing \& developing paragraph \\
Week $_{5}$ & How to review literature \\
Week $_{6}$ & Quiz and assessment \\
& - Outline \\
Contents: & - Material \\
& - Example \\
& - reference for all students \\
\hline
\end{tabular}

The second stage was conducted during week 7 to 12 through also the SCELE-PDE system which facilitates a Step-Function approach for personalization teaching materials base on the knowledge-ability as a treatment for learning the process. It creates a personalized list of learning contents (Level ${ }_{1}$ Level ${ }_{2}$, or Level $_{3}$ ) to be presented to students based on their performance. The stage was used to improve the students' performance (Novice, Average, or Good).

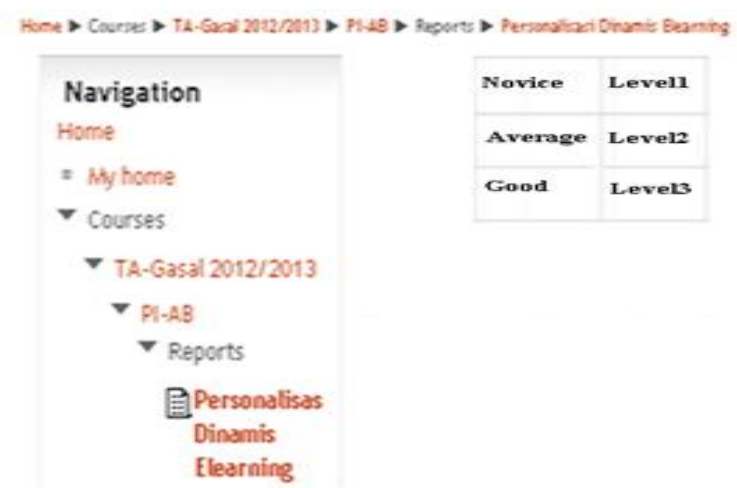

Figure 3. SCELE-PDE interface which facilitates Step-Function approach

Then, Table 5 shows the same topics for learning and contents based on KnowledgeAbility categories, which have been taught to students.

Table 5. Material Levels and Contents based on Knowledge-Ability

\begin{tabular}{llc}
\hline \multicolumn{1}{c}{ Weeks } & \multicolumn{1}{c}{ Topics } & Knowledge-Ability Categories \\
\hline Week $_{7}$ & What is Scientific Writing & Novice; Average; Good \\
Week $_{8}$ & Fundamental concepts of science & Novice; Average; Good \\
Week $_{9}$ & Scientific inquiry and logical thinking & Novice; Average; Good \\
Week $_{10}$ & Writing \& developing paragraph & Novice; Average; Good \\
Week $_{11}$ & How to literature review & Novice; Average; Good \\
Week $_{12}$ & Quiz and assessment & Novice; Average; Good \\
& C Outline and material $\left(\mathrm{LM}_{1}\right)$ for the Good category. \\
Contents: & - Outline, material, and example $\left(\mathrm{LM}_{2}\right)$ for the Average category. \\
& - Outline, material, example, and reference $\left(\mathrm{LM}_{3}\right)$ for the Novice category. \\
\hline
\end{tabular}

\section{Experimental Results}

We carried out experiments in order to evaluate the effectiveness of step-function in the e-learning process. After the experiment was done, in Figure 4 shows, the evaluation results obtained from two stages. We compare the results of the first stage without using the stepfunction approach, and the other stage used the approach. The results demonstrated 
comparison the stage 1, and 2. The assessment of learning outcomes for the novice decreased from 12 to 4 students, and the average also tends reduced from 49 to 34 students. In contrast, the good increased from 39 to 62 students. Thus, most of the student's performance moved from a small category to a higher category in the ability of knowledge.

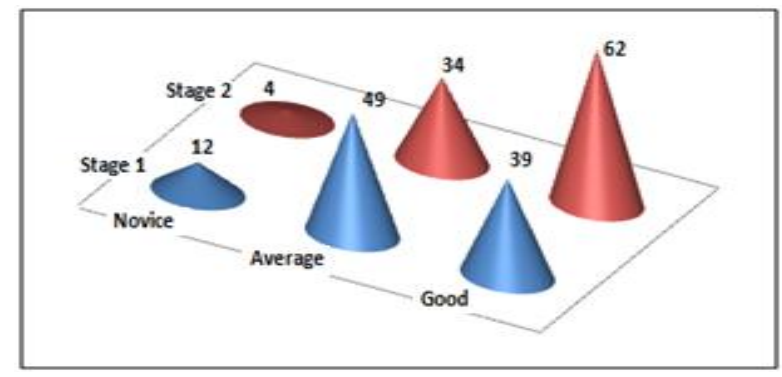

Figure 4.The Evaluation Results Obtained from Two Stages

Although there has not been convincing evidence on the use of a step-function approach to improving student's performance in all courses, the experiment has successfully to improve their performance. This results in line with the majority of similar previous studies on the personalization in e-Learning. Their studies have also proven to be successful in improving the performance of students. For example: Experiment results in the study [11] the proposed epersonalization of web-based learning has helped students to learn more effectively. Experimental results study [12] showed that the proposed personalization course material based on the learner's ability can accelerate learning effectiveness. A comparison between the courses with and without the personalized e-Learning system can see students who passed the exams has grown after the used to the introduction of the system, and led to a relevant increase in the percentage of students who successfully completed a test [13].

\section{Conclusion}

This paper described the step-function approach in e-Learning personalization. In this study, the approach was proposed for personalized in an e-Learning (SCELE-PDE). The approach has adjusted the students with different the ability of knowledge category of a suitable learning material in the SCELE-PDE. The Step-Function approach provided the teaching materials to suit each student knowledge-ability, namely: (1) good category, required to provide materials Level ${ }_{1}$; (2) average category, required to provide materials Level $_{2}$; and (3) novice category, required to provide materials Level $_{3}$.

The approach can be used to support a personalization in e-Learning. Experiment finding obtained from the difference the results of two stages. The Stage 1, without learning personalization, and Stage 2 using it. The result of the study showed that the approach successfully improved student's performance through the e-Learning personalization (SCELEPDE). Currently, we are providing the step-function of learning contents within a "Scientific Writing" course. As a future work, we will use several courses, making the findings more widely applicable.

\section{References}

[1] Cakir O, Simsek. A comparative analysis of the effects of computer and paper-based personalization on student achievement. Computers \& Education. 2010; 55(4): 1524-1531.

[2] Khan FA, Graf S, Weippl ER, Tjoa AM. Implementation of affective states and learning styles tactics in web-based learning management systems. In Advanced Learning Technologies (ICALT), IEEE 10th International Conference. 2010: 734-735.

[3] Bates ET, Wiest LR. Impact of Personalization of Mathematical Word Problems on Student Performance. Mathematics Educator. 2004; 14(2): 17-26.

[4] Chen LH, Lai YC, Weng YH. Intelligent e-learning system with personalized misconception diagnose and learning path guidance. In International Conference on Electronic Business. Macaw. 2009. 
[5] Essalmi F, Ayed LJB, Jemni M, Graf S. A fully personalization strategy of E-learning scenarios. Computers in Human Behavior. 2010; 26(4): 581-591.

[6] Yarandi M, Jahankhani H, Tawil ARH. A personalized adaptive e-learning approach based on semantic web technology. Webology. 2013; 10(2): 1-14.

[7] Sfenrianto, Hasibuan ZA, Suhartanto H, Selviandro N. An Approach to Detect Learning Types Based on Triple-Factor In e-Learning Process. Journal of Next Generation Information Technology. 2014; $5(1)$.

[8] Sfenrianto, Suhartanto H, Hasibuan ZA. A dynamic personalization in e-learning process based on triple-factor architecture. Proceedings 8th International Conference on Computing Technology and Information Management (ICCM). 2012: 1; 69-75.

[9] Tseng JC, Chu HC, Hwang GJ, Tsai CC. Development of an adaptive learning system with two sources of personalization information. Computers \& Education. 2008; 51(2); 776-786.

[10] Milosevic D, Brkovic M, Bjekic D. Designing lesson content in adaptive learning environments. International Journal of Emerging Technologies in Learning (iJET). 2006; 1(2).

[11] Chen CM, Duh LJ. Personalized web-based tutoring system based on fuzzy item response theory. Expert Systems with Applications. 2008; 34(4): 2298-2315.

[12] Baylari A, Montazer GA. Design a personalized e-learning system based on item response theory and artificial neural network approach. Expert Systems with Applications. 2009; 36(4): 8013-8021.

[13] Salahli MA, Özdemir M, Yasar C. Concept Based Approach for Adaptive Personalized Course Learning System. International Education Studies. 2013; 6(5): 92-103.

[14] Abraham G, Balasubramanian V, Saravanaguru RK. Adaptive e-learning environment using learning style recognition. International Journal of Evaluation and Research in Education (IJERE). 2013; 2(1): 23-31.

[15] El-Bakry HM, Saleh AA. Adaptive e-learning based on learner's styles. Bulletin of Electrical Engineering and Informatics. 2013; 2(4): 240-251

[16] Hidayat A, Utomo VG. Adaptive Online Module Prototype for Learning Unified Modelling Language (UML). International Journal of Electrical and Computer Engineering, 2016; 6 (6): 2931-2938.

[17] Cahyani AD, Basuki A, Rohman EM, Kustiyahningsih Y. Design an Adaptive E-learning Application Architecture based on IEEE LTSA reference model. TELKOMNIKA Indonesian Journal of Electrical Engineering. 2015; 13(1): 284-289. 